\title{
Gene therapy for respiratory diseases: potential applications and difficulties
}

The use of genetic materials for treatment is a relatively simple concept which, if successful, could revolutionise the management of both inherited and acquired disease. The aim is to modify production of a specific protein either through upregulation by introducing the DNA of interest, or downregulation through the use of antisense oligonucleotides. Such modification could be for long term correction of an inherited genetic defect such as cystic fibrosis or $\alpha_{1}$-antitrypsin deficiency, on the one hand, or an acquired defect such as cancer on the other. Alternatively, short term modification of protein production could be used to alter inflammation in conditions such as asthma and oxidant-mediated lung injury. Although the concepts are simple, the technology is complex and poorly understood, and it will be some time before gene therapy is routinely available in clinical practice. This editorial outlines the technology of gene transfer and reviews progress towards therapy for the three lung conditions with approved gene therapy protocols, namely cystic fibrosis, $\alpha_{1}$-antitrypsin deficiency, and lung cancer.

\section{Gene transfer techniques}

Gene transfer requires two principal components - the cDNA of interest linked to an appropriate promoter, and a gene transfer agent to facilitate entry into the cell. Most current studies use "ubiquitous" promoters such as SV40, CMV and RSV which are derived from eukaryotic viruses and, in theory, are active in any nucleated cell. Lung specific promoters such as SP-C (surfactant protein C) and CC 10 (Clara cell) are also being investigated. ${ }^{1}$ There has, to date, been relatively little work done to define the relative advantages of the different promoters. It is likely, however, that cell specificity will prove to be valuable as it will limit gene expression to a desired cell population and may also be easier to control.

The two main approaches being investigated with regard to gene transfer agents are the use of viruses and liposomes. Each has certain advantages and problems and future systems may combine the best features of both.

Retroviruses can produce efficient gene transfer, including the integration of the DNA into the host genome. These viruses are well suited to ex vivo transfection of cells which are removed from the body and then replaced in a modified form as, for example, for hepatocytes and production of $\alpha_{1}$-antitrypsin considered below. They are, however, unsuitable for topical lung delivery since they only transfect dividing cells and not the terminally differentiated airway epithelium. Furthermore, in vivo use may carry the risks of germ line transfection and the induction of other unwanted changes by virtue of their random integration into the host genome.

Adenoviruses have the advantage of being trophic for the respiratory epithelium and should, in theory, produce relatively efficient gene transfer to the airways. However, two principal concerns about their use centre around safety and efficacy on repeated administration. Portions of the virus's own genome are deleted, partly to provide space for the gene of interest to be inserted and partly to produce a replication incompetent virus. The principal problem relates to the viral coat proteins which are immunogenic and which result in the production of inflammation through cytotoxic $\mathrm{T}$ lymphocytes or neutralising antibodies re- ducing the efficiency and duration of repeated applications. ${ }^{2}$ A second theoretical risk is recombination with a wild type virus which might restore the ability to replicate and cause infection. Increasingly extensive deletions of the viral genome are therefore being investigated to reduce immunogenicity and replication potential. ${ }^{3}$

Liposomes are lipid vesicles which form spontaneously when certain lipid preparations are mixed in polar solutions. Cationic liposomes form complexes with DNA (which has a net negative charge) and have been used for some years for in vitro gene transfer. Liposomes are relatively inefficient at gene transfer compared with viral vectors but have some major advantages. They have low toxicity and are unlikely to provoke inflammation or to initiate an immune reaction on repeated administration. Liposomes have complex physicochemical properties which are only poorly understood and which probably underlie their variable performance in gene transfer experiments. $^{4}$

\section{Administration of gene transfer systems}

Nebulisation is likely to be the most acceptable delivery system for routine repeated application to the lower airways in man. It has the advantages of widespread deposition which can, to a limited extent, be controlled by varying droplet size. Contact time may also be enhanced by prolonged nebulisation, important in the light of mucociliary clearance within the airways. A theoretical disadvantage is the considerable mechanical stress applied to the liquid during the process of nebulisation. This might damage the gene transfer agent and, in particular, might alter the structure of a liposome-DNA complex. The presence of mucus and airway surface liquid further complicates predictions of whether efficient delivery can be achieved, particularly since purulent secretions contain DNases. The mucus layer may impair access to the cell surface, whilst the aqueous layer may dilute and alter the composition of any topically applied liquid. A recent report of pulmonary epithelial gene transfer following intravenous injection of a liposome-reporter gene complex is tantalising ${ }^{5}$ and, if repeatable, suggests the possibility of other gene transfer strategies. One potential disadvantage is widespread gene transfer to other organs, but organ or cell specific promoters or targeted gene transfer may help to overcome this difficulty.

\section{Gene therapy for cystic fibrosis}

Gene therapy for cystic fibrosis has become a possibility since the isolation of the gene in $1989 .{ }^{6}$ The protein coded for by this gene, cystic fibrosis transmembrane conductance regulator (CFTR), functions as a cAMP-regulated chloride channel on the mucosal surface of the airway epithelium. ${ }^{7}$ Initial studies demonstrated that $C F T R$ gene transfer into cystic fibrosis cells in vitro could correct this chloride defect. ${ }^{89}$ Using both adenovirus ${ }^{10}$ and liposome ${ }^{11}$ mediated gene transfer it was subsequently demonstrated that the CFTR gene could be expressed in the airways of normal mice in vivo. Instillation of the CFTR gene into the lungs was followed by appearance of mRNA at day 1 , with expression sustained for up to four weeks. Transgenic cystic fibrosis mice have also been used to assess CFTR gene transfer in vivo. Thus, both instillation ${ }^{12}$ and . , 
nebulisation ${ }^{4}$ of $C F T R$-liposome complexes into the lungs of these animals has been shown to correct the chloride defect. However, the relatively large amounts of DNA used and the variability of correction suggest that inefficient gene transfer may be a problem with liposome-based systems. A number of studies using non-human primates have also reported CFTR expression following adenoviral-mediated gene transfer. ${ }^{1314}$

With respect to safety it is clear that, as discussed above, airway inflammation develops with increasing adenoviral titre administered. To date, liposome administration has not demonstrated any safety problems. Whether overexpression of CFTR is detrimental has been studied in a number of ways. Transgenic mice expressing the human CFTR gene in the distal airways and alveolar cells showed no adverse effects in terms of lung weight, morphology, or somatic growth. ${ }^{15}$ However, in vitro studies have shown a correlation between high CFTR expression and growth arrest of an epithelial cell line, whilst injection of rabbit embryos with CFTR cDNA caused the majority of the male offspring to be stillborn. ${ }^{16}$ Germ line insertion of the CFTR cDNA administered to the airways is more a theoretical than a real risk. CFTR is probably expressed in the gonads of non-cystic fibrosis subjects ${ }^{17}{ }^{18}$ and males with cystic fibrosis are infertile. Furthermore, no germ line transfer was observed in primates following adenoviralmediated reporter gene transfer to the lungs. ${ }^{14}$ These studies cannot, of course, exclude the possibility of such an event occurring very rarely.

Early data are beginning to appear from human studies. Zabner et $a l^{19}$ studied adenovirus-mediated CFTR cDNA gene transfer to the nose of three volunteers with cystic fibrosis. A degree of localised inflammation around the site of application was seen, probably related to the method of delivery. CFTR mRNA could be demonstrated in two of the subjects, whilst evidence for correction of the chloride abnormality was suggested. These changes lasted up to 10 days after the single application, although the study was not designed to assess duration of expression. Crystal et al have studied CFTR expression in the lungs of four patients following adenoviral-mediated gene transfer by direct instillation. ${ }^{20}$ CFTR was shown in the cells taken from one of the patients, but mRNA could not be demonstrated. Assessment of correction of the chloride defect in the lungs was not attempted. One patient developed an episode of fever, hypotension and evidence of lung infiltrates probably related to the high viral titre administered. These changes reverted to normal over a 28 day period. We have recently completed a double blind placebo controlled trial of liposome-mediated CFTR cDNA gene transfer to the nasal epithelium in 15 delta 508 homozygous cystic fibrosis subjects (nine CFTR cDNA, six placebo). ${ }^{21}$ No safety problems were encountered either in the routine clinical assessment or by a blinded, semiquantitative analysis of nasal biopsies. Both plasmid DNA and CFTR mRNA were detected from the nasal biopsies in five of the eight treated patients. A significant $20 \%$ increase towards normal values was seen in the chloride measurements, with values reverting to cystic fibrosis values by approximately seven days. A number of other studies are underway and, whilst these early changes are encouraging, efficiency of gene transfer is likely to need improvement.

\section{Gene therapy for $\alpha_{1}$-antitrypsin (AAT) deficiency}

Although gene therapy approaches for this condition began at the same time as those for cystic fibrosis, progress has been slower. Since $\alpha_{1}$-antitrypsin is a circulating protein normally synthesised in the liver, it is not clear whether the gene should be targeted at the liver to mimic the normal situation or at the lungs in order to achieve only local antiprotease protection. Furthermore, in comparison with cystic fibrosis it is likely that high levels of protein production will be required. These factors, as well as the uncertain progression of pulmonary disease even in the absence of a smoking history, make gene therapy for $\alpha_{1}$ antitrypsin deficiency a more difficult prospect than for cystic fibrosis.

Several different cell types have been transfected in vitro with the human $A A T$ gene including canine hepatocytes, ${ }^{22}$ sheep endothelium, ${ }^{23}$ and cotton rat airway epithelium. ${ }^{24}$ In each case reasonable levels of transfection ranging from $25 \%$ to $90 \%$ of cells was achieved with production of human $A A T$ mRNA and secretion of protein. In some of these studies protein function was shown as inactivation of neutrophil elastase. Hepatocytes transfected with retroviruses ex vivo have been retransplanted into dogs and human $A A T$ mRNA detected for up to 47 days; low levels of protein production could be shown for 14 days. ${ }^{22}$ In sheep, segments of ligated vessels perfused with adenovirus $A A T$ cDNA for 15 minutes produced protein within the endothelial cells detectable for up to 14 days, but no human AAT could be detected in the circulating blood. ${ }^{23}$ In the cotton rat direct instillation of adenovirus $A A T \mathrm{cDNA}$ into the lungs was followed by detection of the human protein in airway lining fluid, but only at $2 \%$ of the required level for function. ${ }^{24}$ Finally, rabbits receiving liposome-AAT complexes, either by intravenous injection or nebulisation, demonstrated human $A A T$ mRNA and protein in both liver and lungs, again at low levels. ${ }^{25}$

Based on these studies one human gene therapy protocol has been submitted to the regulatory authorities in the USA. This will first assess whether topical application of liposome-AAT complexes into the nasal epithelium of subjects with $\alpha_{1}$-antitrypsin deficiency results in detectable mRNA and protein, and whether any histological changes are seen as a result of gene transfer. Subsequently, the study aims to deliver the complex into the lower airways of subjects scheduled for elective pneumonectomy. Three days before surgery the complex will be instilled bronchoscopically and the site of exposure marked with a dye. At the time of surgery the transfected area will be lavaged for assessment of $\alpha_{1}$-antitrypsin levels and the specimen examined for mRNA and protein.

\section{Gene therapy for lung cancer}

As for other tumours, a number of gene therapy strategies are potentially applicable to lung cancer. Increasing tumour immunogenicity by local expression of, for example, cytokines may lead to increased killing via cytotoxic $\mathrm{T}$ lymphocytes. Furthermore, overexpression of HLA antigens such as B7 on the tumour cells may produce similar effects. Both of these strategies can be achieved by removal of tumour cells with ex vivo transfection with the appropriate gene and, following irradiation, reimplantation of these cells at the tumour site. Direct in vivo gene transfer into the tumour is an alternative means of gene delivery. The interleukin 4 gene has been successfully introduced into human non-small cell (NSCC) tumour cells in vitro using retroviruses. ${ }^{26}$ Murine lung cancer cells transfected with the interferon- $\gamma$ gene have been shown to reduce the number of established metastases in a mouse model. ${ }^{27} \mathrm{~A}$ human trial of liposome-mediated interleukin 2 gene transfer for small cell lung cancer has been submitted to the regulatory authorities in the USA.

A second strategy is to upregulate the production of tumour suppressor genes. $p 53$ is a protein involved in DNA repair and synthesis, and mutations in this gene have been shown to be an independent poor prognostic factor in lung 
cancer. ${ }^{28} p 53$ mutations are estimated to be present in approximately $50 \%$ of all types of lung tumours. Retroviral or adenoviral introduction of the $p 53$ gene into NSCC in vitro reduced growth rate by up to $80 \%$, but only in cell lines with $p 53$ mutations. ${ }^{29}$ Furthermore, in nude mice injected intratracheally with tumour cells, $75 \%$ developed tumours. However, in mice injected three days later with adenoviral $p 53$ constructs this progression only occurred in $25 \%$. Recently a proposal for a human trial to express $p 53$ in NSCC has been given approval in the USA.

An opposite approach is the downregulation of oncogene expression. The K-Ras gene produces a protein $\mathrm{p} 21$ involved in cellular signal transduction. Approximately $30 \%$ of lung adenocarcinomas have mutations in the $\mathrm{K}-\mathrm{Ras}$ gene, and again this is an independent poor prognostic factor in these cases. ${ }^{30}$ Transfection of the K-Ras antisense gene into NSCC in vitro produces up to 10 -fold growth inhibition, but only in K-Ras mutant cell lines. Again with intratracheal tumour cell injection into nude mice, $\mathrm{K}$-Ras antisense reduced tumour formation from $90 \%$ to $13 \% .^{31}$ A proposal for introduction of $\mathrm{K}-$ Ras antisense into human NSCC has been submitted.

Finally, introduction of "suicide" genes has been suggested as treatment for many types of cancer. One example is the thymidine kinase (TK) enzyme, the viral but not the mammalian form of which metabolises ganciclovir to its monophosphate. The mammalian form metabolises the monophosphate to the triphosphate which competes with nucleotides for DNA replication leading to cell death. Thus, introduction of the viral form of the $T K$ gene renders cells susceptible to ganciclovir. Furthermore, an important phenomenon known as the "bystander effect" means that not all tumour cells need to be transfected. As long as about $10 \%$ of cells within a tumour are transfected, the surrounding non-transfected cells are also killed by ganciclovir; the most likely explanation of this is cell to cell passage of the ganciclovir monophosphate. The ganciclovir concentration needed for cell killing is approximately that achieved in the treatment of cytomegalovirus infection with this agent. Adenovirus-mediated herpes simplex $T K$ has been used to transfect human mesothelioma cells in vitro, and subsequent administration of ganciclovir produced virtually $100 \%$ cell death. ${ }^{32}$

Clearly, one of the major challenges for gene therapy of lung cancer using any of these potential techniques is the ability to target metastatic diseases in addition to the initial tumour mass. Given the current difficulties with gene transfer into any cell type in vivo, such selective targeting suggests that gene therapy for lung cancer will be the most difficult goal of the three diseases outlined above.

\section{Conclusions}

At present the biggest hurdles for establishing gene therapy in clinical practice are efficient in vivo gene transfer and the molecular knowledge of which genes are most usefully targeted in a given acquired disease. Many laboratories are trying to improve the former, and rapid progress is being made in the development of new gene transfer agents. The aim for respiratory diseases is to produce efficient targeted transfer of the gene or antisense oligonucleotide of choice into either the pulmonary epithelium or endothelium. If this can be achieved gene therapy for both inherited and acquired lung diseases is likely to be a realistic therapeutic option in the future.

National Heart and Lung Institute and Royal Brompton Hospital, London SW3 $6 L R$,

UK
ERIC W F W ALTON
DUNCAN M GEDDES
1 Wert SE, Glasser SW, Korfhagan TR, Whitsett JA. Transcriptional elements from the human SP-C gene direct expression in the primordial respiratory epithelium of transgenic mice. Dev Biol 1993;156:426-43.

2 Trapnell B. Adenoviral vectors for gene transfer. Adv Drug Deliv Rev 1993; 12:185-99.

3 Yang Y, Nunes FA, Berencsi K, Gonczol E, Engelhardt JF, Wilson JM. Inactivation of $\mathrm{E} 2 \mathrm{a}$ in recombinant adenoviruses improves the prospect for gene therapy in cystic fibrosis. Nature Genetics 1994;7:362-9.

4 Alton EWFW, Middleton PM, Caplen NJ, Smith SN, Steel DM, Munkonge O FM, et al. Non invasive liposome mediated gene delivery can correct the $\underset{x}{\mathscr{D}}$ ion transport defect in cystic fibrosis mutant mice. Nature Genetics 1993; ' 5:135-42.

5 Zhu N, Liggit D, Lui Y, Debs R, Systemic gene expression after intravenous DNA delivery into adult mice. Science 1993;261:209-11.

6 Riordan JR, Rommens JM, Kerem, B-S, Alon N, Rozmahel R, Grzelcezak $\mathrm{Z}$, et al. Identification of the cystic fibrosis gene: cloning and characterisation of complementary DNA. Science 1989;245:1066-73.

7 Welsh MJ. Abnormal regulation of ion channels in cystic fibrosis epithelia. FASEB f 1990;4:2718-25.

8 Drumm ML, Pope HA, Cliff WH, Rommens JM, Marvin SA, Tsui L-C, ஹ et al. Correction of the cystic fibrosis defect in vitro by retrovirus-mediated gene transfer. Cell 1990;62:1227-33.

9 Rich DP, Anderson MP, Gregory RJ, Cheng SH, Paul S, Jefferson DM, et al. Expression of cystic fibrosis transmembrane conductance regulator $\vec{\omega}$ corrects defective chloride regulation in cystic fibrosis airway epithelial $\mathcal{D}$ cells. Nature 1990;347:358-63.

10 Rosenfeld MA, Yoshimura K, Trapnell BC, Yoneyama K, Fukayama M, Stier LE, et al. In vivo transfer of the human CFTR gene to the airway of epithelium. Cell 1992;68:143-55.

11 Yoshimura K, Rosenfeld MA, Nakamura H, Scherer EM, Pavirani A, o Lecocq J-P, et al. Expression of the human CFTR gene in the mouse lung + after in vivo intratracheal plasmid mediated gene transfer. Nucleic Acids Res $1991 ; 20: 3233-40$.

12 Hyde SC, Gill DR, Higgins CF, Trezise AE, MacVinish LJ, Cuthbert AW, 음 et al. Correction of ion transport defect in cystic fibrosis transgenic mice by gene therapy. Nature 1993;362:250-5.

13 Engelhardt JF, Simon RH, Yang Y, Zepeda M, Weber-Pendleton S, Doranz $B$, et al. Adenovirus-mediated transfer of the CFTR gene to lung of nonhuman primates: biological efficacy study. Hum Gene Therapy 1993;4: $\vec{\theta}$ 759-69.

14 Bout A, Perricaudet M, Baskin G, Imler J, Scholte BJ, Pavirani A, Valerio of D. Lung gene therapy: in vivo adenovirus-mediated gene transfer to rhesus monkey airway epithelium. Hum Gene Therapy 1994;5:3-10

15 Whitsett JA, Dey CR, Stripp BR, Wikenheiser KA, Clark JC, Wert SE, et al. Human CFTR directed to respiratory epithelial cells of transgenic $\overline{\bar{O}}$ mice. Nature Genetics 1992;2:13-20.

16 Schiavi SH, DiTullio P, Abdelkader N, Cunniff M, Reber S, Meade H, et al. Evidence for toxic effects of overexpression of CFTR in vitro and in ( vivo. 7th North American CF Conference 'Late Breaking Science" 1993.

17 Tizzano EF, Chitayat D, Buchwald M. Cell-specific localisation of CFTR $\bar{O}$ mRNA shows developmentally regulated expression in human fetal tissues. Hum Mol Genet 1993;2:219-24.

18 Tresize AEO, Chambers JA, Wardle CJ, Gould S, Harris A. Expression of the cystic fibrosis gene in human foetal tissues. Hum Mol Genet 1993;2: 213-8.

19 Zabner J, Couture LA, Gregory RJ, Graham SM, Smith AE, Welsh MJ. Adenovirus-mediated gene transfer transiently corrects the chloride transport defect in nasal epithelia of patients with CF. Cell 1993;75:207-16.

20 Crystal RG, McElvaney NG, Rosenfeld MA, Chu C-S, Mastrangeli A, Hay $\mathrm{JG}$, et al. Administration of an adenovirus containing the human CFTR cDNA to the respiratory tract of individuals with cystic fibrosis. Nature Genetics 1994;8:42-51.

21 Caplen NJ, Alton EWFW, Middleton PG, Dorin JR, Stevenson BJ, Gao $\mathrm{X}$, et al. Liposome-mediated CFTR gene transfer to the nasal epithelium $\mathrm{O}$
of patients with cystic fibrosis. Nature Medicine $1995 ; 1: 39-46$.

22 Kay MA, Baley P, Rothenberg S, Leland F, Fleming L, Ponder KP, et al. Expression of human $\alpha_{1}$-antitrypsin in dogs after autologous transplantation of retroviral transduced hepatocytes. Proc Natl Acad Sci 1992; 89:89-93.

23 Lemarchande $P$, Jones $M$, Yamada I, Crystal R. In vivo gene transfer and 0 expression in normal uninjured blood vessels using replication deficient $N$ recombinant adenovirus vectors. Circ Res 1993;72:1132-8.

24 Rosenfeld MA, Siegfried W, Yoshimura K, Yoneyama K, Fukayama M, W Stier L, et al. Adenovirus-mediated transfer of a recombinant $\alpha_{1}$-antitrypsin $\sigma$ gene to the lung epithelium in vivo. Science 1991;252:431-4.

25 Canonico AE, Conary JT, Meyrick BO, Brigham KL. Aerosol and intravenous transfection of human $\alpha_{1}$-antitrypsin gene to lungs of rabbits. $A m$ f Respir Cell Mol Biol 1994;10:24-9.

26 Hunt JD, Pippin BA, Landreneau, Jacob WF, Lotze MT, Siegfried JM." Transfer and expression of the human interleukin-4 gene in carcinoma and stromal cell lines derived from lung cancer patients. $\mathcal{F}$ Immunotherapy $\mathrm{O}$ and stromal cell

27 Ponar A, Tzehoval E, Vadai E, Feldman $M$, Eisenbach L. Im- $\varrho$

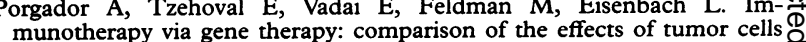
transduced with the interleukin-2, interleukin-6, or interferon- $\gamma$ genes. $\mathcal{F}_{O}$ Immunotherapy 1993;14:191-201.

28 Harris CC, Hollstein M. Clinical implications of the $p 53$ tumor-suppressor gene. Eng f Med 1993;329:1318-27.

29 Zhang W-W, Fang X, Mazur W, French BA, Georges R, Roth JA. High efficiency gene transfer and high-level expression of wild-type $p 53$ in human lung cancer cells mediated by recombinant adenovirus. Cancer Gene Therapy 1994;1:5-13.

30 Zhan Y, Mukp vector-mediated transduction of K-ras antisense RNA into human lung vector-mediated transduction of K-ras antisense RNA into human lung cancer cells inhibits exp

31 Georges R, Mukhopadhyay T, Zhang Y, Yen N, Roth JA. Prevention of orthotopic human lung cancer growth by intratracheal instillation of a retroviral antisense K-ras construct. Cancer Res 1993;53:1743-6.

32 Smythe WR, Kaiser LR, Hwang HC, Amin KM, Pilewski JM, Ech SJ, et al. Successful adenovirus-mediated gene transfer in an in vivo model of human malignant mesothelioma. Ann Thorac Surg 1994;57:1387-94. 